\title{
A TOP-DOWN APPROACH TO AN ARMOURED FACE CONVEYOR FAMILY DESIGN
}

\author{
Guoping $\mathrm{Li}^{1,2}$, Huangao Zhang ${ }^{1}$, Wenyan $\mathrm{Zhao}^{3}$, Haixian $\mathrm{Zhao}^{1}$, Runhua \\ $\operatorname{Tan}^{1}$ \\ ${ }^{\prime}$ School of Mechanical Engineering, Hebei University of Technology, Tianjin, 300130, \\ PRC ; Email: Zhgzwy@sina.com ${ }^{2} Z$ Zhangjiakou Coal Mining Machinery Co. Ltd, \\ Zhangjiakou,075025, $P R C$; ${ }^{3}$ School of Management, Hebei University of Technology, \\ Tianjin, 300130, $P R C$
}

Abstract: The Armored Face Conveyer is typical product for customization. To achieve Mass customization, a top-down approach to product family design is introduced. The steps and tools of the approach are discussed when it is used to design AFC family. The key of the approach includes three aspects: the object product is classified in series according to the main parameters of the product; each series build a platform as the design frame; a database is build to deploy variants. After the platforms are built, software is developed to implement the process of variant deployment. With the help of the software, the design and manufacture periods are much shortened.

Key words: Armed Face Conveyer (AFC); product platform; product family; variant; variant deployment, software

\section{INTRODUCTION}

The Armored Face Conveyor (AFC) is one of important conveying equipment used at coal mining face under ground. Many restrictions for AFC design couldn't predefine and a number of uncertain elements influence the product design and manufacture, then the AFC is typical product for customization. In order to obtain new products more efficiently and effectively, it is essential for the AFC to implement Mass Customization. In most case the AFC design is variants design that the variant use an existing product as a prototype. There are many common parts between different variant. It is feasible to implement Mass Customization.

Please use the following format when citing this chapter:

Li, Guoping, Zhang, Huangao, Zhao, Wenyan, Zhao, Haixian, Tan, Runhua, 2006, in International Federation for Information Processing (IFIP), Volume 207, Knowledge Enterprise: Intelligent Strategies In Product Design, Manufacturing, and Management, eds. K. Wang, Kovacs G., Wozny M., Fang M., (Boston: Springer), pp. 1010-1015. 

Design

A good way to achieve Mass Customization is to build one or more effective product platforms. As Mayer and Lehnerd defined "A product platform is a set of subsystems and interfaces that form a common structure from which a stream of derivative products can be efficiently developed and produced". (Mayer and Lehnerd, 1997) Every product derived from the platform is a "variant" and all the variants form a product family.

\section{A TOP-DOWN APPROACH TO PRODUCT FAMILY DESIGN}

Simpson classifies the approaches of product family design into two types: bottom-up and top-down approaches.(Simpson,1997) The two approaches are different in the way of product platform building. In the former the product platform is built by the way that a group of distinct products were redesigned or consolidated to realize components standardization without significantly compromising product quality and performance. In the latter the subsystems of all existing products in a company are integrated into one or more product platforms and the new product development must surround that or those platforms. Because the capital investment and redesign costs can be significant when the bottom-up approach is carried out, most companies would rather adopt the top-down approach to design their product family.According to the character of AFC, a top-down approach to design AFC family is put forward, which steps was shown in figure 1.

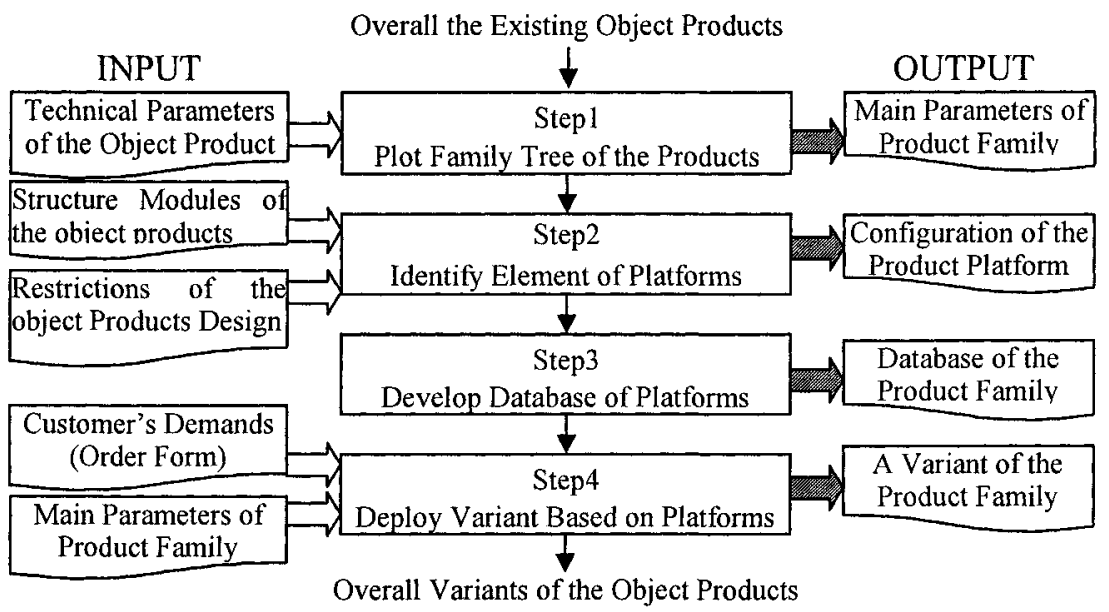

Figure I. the steps of a top-down approach to design product family 
The four steps of the approach show four key problems to obtain mass customizations. The method to solve this four problem will be discussed together with AFC in next section.

\section{AFC FAMILY DESIGN}

AFC family is designed according to above-mentioned approach.

\subsection{AFC Family Tree Plotting}

Because the requirement of output and the applied environment vary greatly, each individuals of AFC vary greatly from each other in the performance parameter and structure measures. But if it is well planed the variants have chance to be compartmentalized in series. Individuals in same series should be same in the main parameters and most parts, close in performance parameters and architecture parameters. Then each series should build a platform as a common frame of the AFC design. All the platforms with their variant can integrate into a product family tree.

The key to plot product family tree is to identify the main parameters by which one group is distinguished from others. The main parameters can be one or more performance index or structure measures. Many methods can be used to identify the main parameters for a set of product, such as AHP, Pareto diagram, HOQ etc.

The main function of AFC is to carry coal, so output capacity is a primary technical parameter. While output capacity depend on the width of the line pan and the chain speed. And the range of the chain speed design is very small. Then the width of the line pan represents the ability of the conveyor and can be used as a main parameter.

Considering all the AFC with the same width of pans, they differ greatly in the measure of power, the flight-bar type and chain size and design length. The $\Sigma$ type of pan, power, design length both relate to chain size and the flight-bar type are same in most part. After analyze the structures of the AFC, the individuals with the same width of pan, chain size and the flight-bar type only differ in a few parts. Therefore the main parameters include the width of pan, chain size and the flight-bar type. According to those three parameters the existing AFC is classified into 26 series. Then 26 platforms should be built for each series, and each platform is a branch of the AFC family tree. 
Design

\subsection{Product Platform Building for AFC}

As shown by figure 2, a variant derived from a platform compose of two parts: parts from platform and parts of customization. (Zhang,2003)
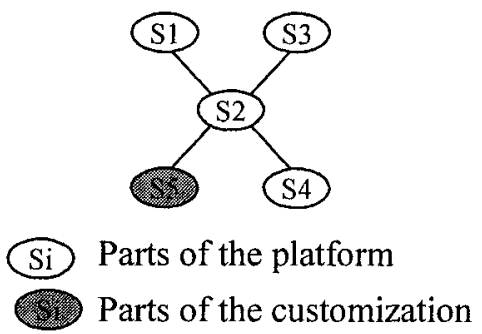

Figure 2. The configuration of a variant of a platform

From the definition of product platform the platform can be seen as the common items shared by a set of products. Therefore, the essential of product platform building can be seen as a process that the common items are identified by some means. Considering in reverse, if the parts of customization are identified, the rest parts could integrate into a platform. Because all AFC have similar configuration, once a platform for a series is built, other platforms are the same in configuration. One series were used to study object to build a platform. By identifying the parts of customization, the process of product platform design should include four steps (as shown in figure 3 ).

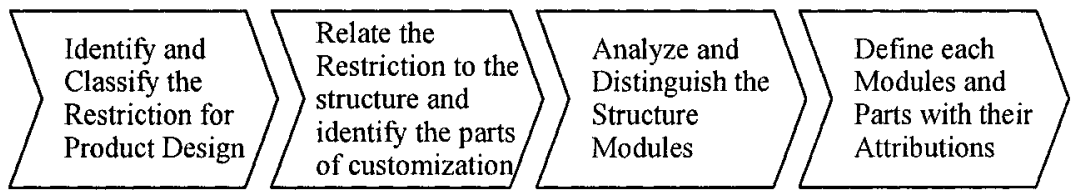

Figure 3. Four steps of product platform building

The structure change result from the change of design restriction that can be extracted from the demands of customers. First, the customers' demands should be studied carefully to find out the items that changed irregularly as restrictions for variants design. Second, the restrictions for variants design should relate to the structure of the product and find out the parts that relate to those restrictions. (McAdams, 1998) Third, the object product is decomposed into modules according to its function structure and its physical configurations. The parts identified from the step 3 should depart from others and work as independent modules. Last, the modules should be described by 
attributions for later deployment. In the process QFD can be used to analyze the relationship between two items (Jack, 1998) and the method of modular design can help to identify the modules (Stone, 1997).

The restrictions for variant design of AFC mainly come from the environment, which include the geological situation, the shear, the stage conveyer and the self-advanced hydraulic supports. If well planed, the influence of these restrictions on the structure of AFC can be limited in some parts, such as pushing ear of spilling plate, pushing unit of delivery and return ends, seat of track and so on. Considering the customers sometimes will emphasize on some parts. The module of the platform should be decomposed into parts and define each part or subsystem with some attributions.

\subsection{The Database of the AFC Family Building and Variants Deployment}

After all the platforms are built, each module of a platform should be described by some attributions to distinguish from the same module of the other platform. Some complex modules should be decomposed into smaller subsystems in case that some special requirements result in the change of the modules. All data of AFC of a company has been input the e-database of a PDM system, and the software for variant design has been developed and added to the PDM system (As shown in figure 4).

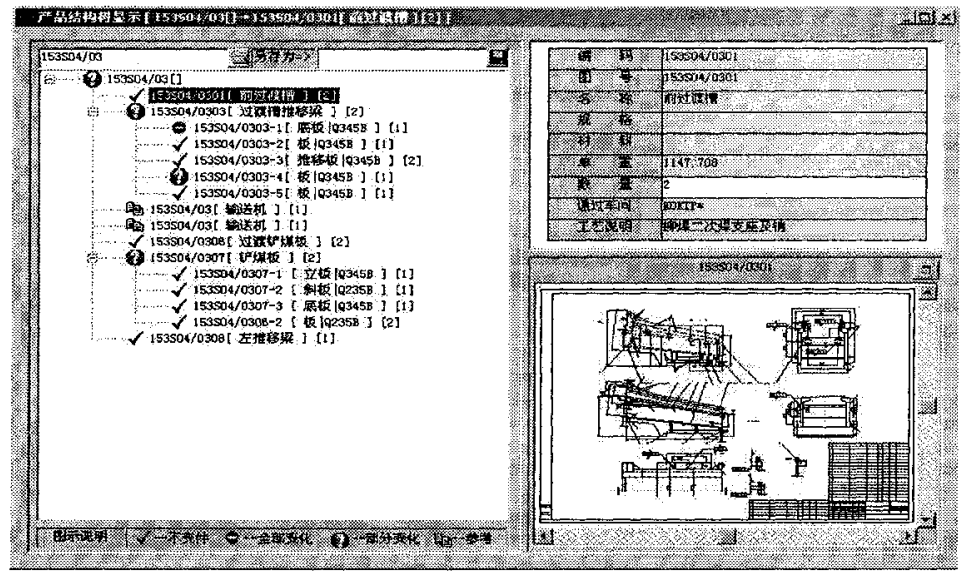

Figure 4. A window of the software for variant deployment 
Design

When the order forms are arrived, the engineers input the main structure parameters and then get a product platform. On the basis of the product platform, the software can deploy a new variant by giving some value of the modules attributions. The parts of the platform can be selected promptly and one or more prototype similar to the parts of the customization can also be found. With the help of the software, the design and manufacture periods are much shortened.

\section{SUMMARY}

A well-defined product platform can succeed in the purpose that the company can provide as much variety as possible for market with as little variety as possible between products.

The Armored Face Conveyer is typical product for customization. To achieve Mass customization, a top-down approach to product family design is introduced. The steps and tools of the approach are discussed when it is used to design AFC family. After the platforms are built, software is developed to implement the process of variant deployment. With the help of the software, the design and manufacture periods are much shortened.

\section{ACKNOWLEDGMENT}

The research is support by Zhangjiakou Coal Mining Machinery Co. Ltd. and also is supported in part by Natural Science Foundation of China (50375045) and Tianjin Natural Science Foundation Key Projects (043802211)

\section{REFERENCES}

1. Meyer M H, Lehnerd A P, 1997, The Power of Product Platforms, USA, Free Press, New York

2. Simpson T. W., 1998, A Concept Exploration Method for Product Family Design, Ph. D Dissertation, Georgia Institute of Technology

3. McAdams D A, Stone R B, 1998, Wood K L. Understanding Product Similarity Using Customer Needs, ASME Design Engineering Technical Conference, DETC98/DTM-5660

4. Zhang Huangao, Zhao Wenyan, etc., 2003, A New Model of the Design Process Using Product Platform/QFD/TRIZ, Proceeding of 2003 International Conference of Integrated Design and Process Technology, IDPT2003

5. Jack B. Revelle, John W. Moran, Charles A. Cox, 1998, The QFD Handbook, USA: John Wiley \& Sons, Inc., New York, pp.3-21

6. Stone R. B., 1997,Towards a Theory of Modular Design, Ph. D Dissertation, University of Texas. 